\title{
Notas sobre projetos urbanos e turismo: o caso de Rio Branco, AC, Brasil
}

\author{
Notes on urban projects and tourism: the case of Rio Branco, AC, Brazil
}

\author{
Thiago Allis (ALLIS, T.) ${ }^{*}$
}

\begin{abstract}
RESUMO - Este artigo tem o objetivo de propor uma melhor compreensão do fenômeno turístico na atualidade em função das questões da urbanização contemporânea e da produção capitalista atual. De maneira geral, discute-se a relação dos projetos urbanos com a atividade turística, tendo como referência analítica a organização produtiva "pós-moderna" e os princípios mais recorrentes de gestão urbana - como a idéia de "empreendedorismo urbano", apontada por Harvey (1996). Para tanto, realizouse um estudo de caso sobre a restauração de áreas ribeirinhas em Rio Branco - Acre (AC/Brasil), no intuito de se observarem localmente questões de urbanização e do turismo contemporâneos - especialmente no que tange às questões de grandes projetos urbanos. Como resultado, nota-se que, num ambiente urbano diverso daqueles das cidades centrais do sistema capitalista ou das "cidades globais", nos termos de Sassen (1991), são empreendidas ações de desenvolvimento turístico em função do re-uso do patrimônio cultural urbano.
\end{abstract}

Palavras-chave: Urbanização contemporânea; Turismo; Projetos urbanos; Rio Branco Acre (AC/Brasil)

ABSTRACT - This article aims to propose a better comprehension of today's tourism phenomenon in face of the contemporary urbanization issues and the capitalist production organization. In general terms, discusses the relation between urban projects and the tourism activity, referring analytically to the "post-modern" production organization and the principles of urban management - such as Harvey's "urban entrepreneurialism" (Harvey, 1996). For such, it was held a study case about some portions of Rio Branco, Acre (AC/Brazil) city's revitalization by Acre River, aiming to understand locally contemporary urbanization and tourism issues - on the frame of large urban projects concepts. As result, it can be pointed out that even in a diverse urban context of those in capitalist system's central cities or the "global cities", as quoted by Sassen (1991), in Rio Branco there have been carried on tourism development actions regarding re-use of urban heritage.

Key words: Contemporary urbanization; Tourism; Urban projects; Rio Branco - Acre (AC/Brazil)

\footnotetext{
* Bacharel em Turismo pela Universidade de São Paulo (USP). Mestre em Integração da América Latina, pelo Programa de Pós-Graduação em Integração da América Latina (PROLAM-USP), doutorando em Arquitetura e Urbanismo pela Faculdade de Arquitetura e Urbanismo (FAU-USP). Professor Assistente do Curso de Turismo da Universidade Federal de São Carlos - campus Sorocaba. Endereço profissional: Rodovia João Leme dos Santos (SP-264), Km 110 (Sala 35) - Bairro Itinga. CEP: 18052-780 - Sorocaba - SP (Brasil). Telefone: (15) 3229-5958 (UFSCar). E-mail: thiagoallis@ufscar.br
} 


\section{INTRODUÇÃO}

O objeto de observação neste artigo representa uma opção pouco convencional do ponto de vista dos estudos de caso de projetos urbanos, pelo menos no ambiente acadêmico. A cidade de Rio Branco, no Acre, apesar de geográfica e economicamente isolada no território brasileiro, vem passando por algumas intervenções urbanas que merecem ser interpretadas à luz das discussões atuais sobre urbanização e capitalismo no Brasil. Neste contexto, a pós-modernidade e todas as questões de organização social e econômica contemporâneas, apesar de condicionadas por elementos universais, se fazem presentes nos diversos territórios de forma diferentes.

$\mathrm{O}$ acesso e tratamento dos temas - aqui discutidos sinteticamente - foram iniciados nos estudos de mestrado ${ }^{1}$ do autor e, agora, passam por um processo de aprofundamento no doutorado, na linha de Planejamento Urbano e Regional, na Faculdade de Arquitetura e Urbanismo da Universidade de São Paulo (FAU-USP). De particular, como aspecto estruturante deste trabalho, o patrimônio ambiental urbano (REIS FILHO, 1994; YÁZIGI, 2000, 2002, 2003) receberá maiores atenções, sempre com a cautela e o interesse em posicioná-lo frente às questões urbanas atuais. Dessa forma, sem sobrevalorizar abordagens centradas no patrimônio histórico - e, assim, correr o risco de não avançar nas contribuições -, priorizaram-se aspectos concernentes à composição urbana como um todo, como sendo esta uma linha de raciocínio mais profícua para a compreensão do turismo nos contextos urbanos.

No que se refere à produção capitalista atual, o turismo paulatinamente ascende à condição de potencial gerador de divisas e, ainda, perspectivas de visibilidade para determinadas cidades e, naturalmente, aos seus gestores. Por sua natureza, o produto turístico - conquanto vinculado à prestação conjunta de vários serviços - exige a presença dos seus consumidores in situ, já que, diferentemente das comoddities e produtos industriais, o resultado da produção não é material, passível de empacotamento e transporte, para posterior consumo.

\footnotetext{
${ }^{1}$ ALLIS, T. Turismo, patrimônio cultural e transporte ferroviário: um estudo sobre ferrovias turísticas no Brasil e na Argentina. Dissertação (Mestrado), Programa de Pós-Graduação em Integração da América Latina, Universidade de São Paulo, 2006.
} 
Para abarcar e interpretar a ampla complexidade da atividade turística, parte-se do princípio que sua compreensão, enquanto fenômeno social e prática de mercado, não pode prescindir da agregação de conhecimentos de outras áreas. Neste caso, os estudos de planejamento urbano e regional - em que pesem os estudos de urbanização e do urbanismo - oferecem arcabouço teórico-metodológico importantes para analisar, de forma crítica, a articulação entre turismo e estruturação do espaço urbano na contemporaneidade.

Independentemente de se assumir o atual momento da urbanização ${ }^{2}$ como expressão plena da pós-modernidade, trata-se de uma observação crítica dos elementos que compõem a organização econômica e social do espaço urbano na contemporaneidade - dentre eles, o turismo. Para tanto, é imprescindível reconhecer e analisar, ainda que de maneira geral, os elementos de natureza social, econômica e política que estão na essência das transformações do sistema de produção capitalista contemporâneo. Harvey $(1996 ; 2005)$ chama de "acumulação flexível" o conjunto de transformações produtivas que se sucedem ao modelo fordista de produção, iniciada na década de 1970 .

Produção e consumo ganham novos contornos, já que a desconcentração industrial e, consequentemente, a própria desindustrialização vão lançar novos desafios do ponto de vista de políticas públicas na gestão urbana. O resultado mais assimilado destas transformações é a migração da força de trabalho e a transformação das economias urbanas em direção ao setor terciário. Do ponto de vista material, as cidades consolidadas no formato industrial são instadas a buscar alternativas no que tange à geração de empregos e riquezas; sem desconsiderar uma estrutura urbana pré-existente que assiste a um processo de obsolescência - fábricas, zonas industriais, ramais ferroviários etc. Mesmo sem estudar detidamente dados e estatísticas oficiais, esta transformação é visível no skyline paulistano: fábricas e chaminés não mais resumem a dinâmica urbana, senão jazem em bairros próximos ao centro, que são paulatinamente incorporados ao mercado imobiliário - a exemplo dos bairros da Barra Funda, da Mooca e do Ipiranga.

\footnotetext{
${ }^{2}$ Para Soja (2000, p. 16) a noção de cityspace implica em uma "forma de vida"; para o autor, "Cityspace [...] involves a much larger and more complex configuration, a specific geography that, by its very definition, tends do be dynamic and expansive in its territorial domain. It will always contain inhabited or, for that matter, uninhabited or wilderness areas that do not look urban in any conventional way, but nonetheless are urbanized, part of a regional cityspace and thereby deeply affected by urbanism as way of life [...]" (grifo nosso).
} 
Canclini (2003) sugere que estes e outros fenômenos contemporâneos se dão em paralelo com a construção de uma "sociedade eminentemente de consumo" - apontando o encaminhamento a uma sociedade pós-moderna, referenciada na re-organização do sistema produtivo nas últimas décadas do século $\mathrm{XX}$, em que o setor de serviços ganha protagonismo. Sem dúvida, para o turismo esta é uma realidade das mais importantes, dadas a natureza de sua composição e as novas demandas do ponto de vista dos consumidores e usuários de serviços turísticos.

Todas essas questões, de alguma forma, estão plasmadas no discurso e na prática da gestão urbana recente, em que pese o papel das estratégias em detrimento do planejamento global, centralizado e eminentemente estatal ${ }^{3}$. Não raro, no mundo em geral e cada vez mais frequentemente no Brasil, governos municipais e lideranças locais se articulam para lançar planos de "revitalização" de áreas específicas das cidades, geralmente com apelo imagético ao patrimônio e, quase sempre, alvo de propostas para atividades de lazer, turismo e entretenimento.

Portanto, a cultura material expressada na paisagem urbana converte-se em instrumento de políticas, programas, planos e projetos de gestão do território, que, a despeito de sua eficácia, são assimiladas pelas pautas de gestores municipais e, gradativamente, pela sociedade, como sendo instrumentos legítimos e adequados para a gestão do território urbano.

\footnotetext{
${ }^{3}$ Para um estudo detalhado sobre o assunto, recomenda-se a leitura de BRENNER, N; THEODORE, N. (orgs.) Spaces of neoliberalism: Urban reestructuring in North America and Western Europe. London: Blackwell, 2002.

${ }^{4}$ Não existe consenso sobre a terminologia aplicada a intervenções urbanas desta natureza, sendo que, em geral, seus críticos apontam uma polarização ideológica, que supervalorizam a capacidade renovadora desses projetos e escamoteiam as questões da dinâmica urbana pré-existente. Uma vez que não é propósito deste artigo fazer uma discussão epistemológica sobre o assunto, os termos "renovação", "requalificação" serão utilizados de maneira indistinta, como forma de referenciar projetos urbanos aplicados a porções delimitadas do tecido urbano, geralmente acompanhados de ações de restauro do patrimônio e implantação de novas estruturas urbanas. Vasconcellos e Mello (2006, p. 64) oferecem uma análise que conjuga "aspectos semânticos" à "crítica de conteúdos", e, ao discutirem o peso do patrimônio cultural nessas intervenções, questionam certo oportunismo político na condução dos projetos: “As várias nomenclaturas dadas aos planos implicam uma grande confusão de conceitos. Concomitantemente, o poder público parece colaborar com essa confusão, legitimando novos termos para manter o privilégio de definir quais culturas a serem selecionadas, associando o tipo de intervenção ao marketing político”.
} 


\section{A CIDADE E A CULTURA NO CONTEXTO PÓS-MODERNO}

A relação entre urbano e turismo não é recente e muito menos questionável. Os países centrais, ao liderar o processo de avanço tecnológico baseado na Revolução Industrial, tornaram-se essencialmente urbanos. A esse processo assistiram a modernização da técnica e a conquista de direitos sociais e trabalhistas, mas também situações de vida degradantes em aglomerações urbanas cada vez mais poluídas e extenuantes.

No período pós-Segunda Guerra Mundial, as transformações do processo produtivo foram impingindo novos desafios à organização do espaço urbano. Ainda que esse processo tenha se desenvolvido com graus de importância variados, a transformação da técnica e as novas relações comerciais e políticas entre os países estimularam a desconcentração e a fragmentação das atividades industriais. Isso, por sua vez, interferiu diretamente na organização do espaço urbano, nas escalas intra-urbana, regional ou nacional.

Agora, as administrações locais - por vezes, articuladas com governos centrais buscam inserir as cidades num circuito de competição por recursos e visibilidade política. Arantes (2001, p. 144-5), ao descrever a importância da "cultura" na gestão urbana, considera:

\footnotetext{
Antes um direito, agora uma obrigação político-administrativa, a cultura tornouse peça central na máquina reprodutiva do capitalismo, a sua nova mola propulsora. Conscientes disso, alguns governos, embora acossados pela crise e pela avalanche neoliberal, não titubearam, por exemplo, em restringir o orçamento do sistema previdenciário e ao mesmo tempo investir no campo cultural em expansão (de retorno seguro e rápido), fundindo publicidade e "animação cultural" (o exemplo máximo foi sem dúvida o da França de Miterrand). (grifo do autor)
}

Silva (2006, p. 25-26) ao tratar das "fronteiras vivas" para a realidade urbana, pressupõe, diferentemente do conceito de limite, "uma reflexão sobre as fronteiras que se estabelecem no espaço urbano entre áreas informais e formais", sem negligenciar sua interdependência. Com isso, pode-se compreender melhor a visão de Argan (1998, p. 74) sobre o peso do patrimônio cultural - especialmente no tocante às áreas centrais - nas intervenções urbanas e o desenvolvimento do turismo: 
O conceito de "centro histórico" pode ter uma utilidade pragmática, mas é um falso conceito. Por que algumas partes da cidade deveriam ser "históricas" e outras "não-históricas"? A cidade é, in toto, uma construção histórica. As próprias deformações e mal-formações urbanas devidas à gestão capitalista são fatos, apesar de não gloriosos, da história da nossa época.

Os projetos de requalificação urbana em Baltimore e do Battery Park, ambos nos EUA, além de Docklands, em Londres, constituem-se como projetos que consubstanciam modelos de gestão urbana baseados em "competitividade e planejamento estratégico" (ARANTES, 2002) e "empreendedorismo urbano" (HARVEY, 2005). Um exemplo recente - pós-Barcelona e pós-Sevilha - é o caso de Bilbao, que converteu-se de tradicional cidade industrial a degradada e pobre e, recentemente, recuperou importância econômica em função de um "urbanismo de regeneração", (RODRIGUEZ; ABRAMO, 2008, p. 128).

Arantes (2002) direciona sérias críticas quanto às formas que esses processos são encaminhados, já que os usos acabam por priorizar os usuários mais "solváveis". É dizer, não somente os espaços, senão também os usuários das novas estruturas e serviços passam a ser selecionados em função de poder de consumo e comportamento. Arantes (2001, p. 125), lembrando experiências européias semelhantes, descreve, de maneira contundente, resultados das medidas "preparatórias" para o turismo nesses contextos:

\begin{abstract}
O acesso aos "lugares" requalificados tornava-se uma impossibilidade de fato para os habitantes expulsos das regiões em que se concentravam os antigos centros nobres e administrativos das cidades e cuja deterioração subseqüiente transformara em cortiço e refúgio dos homeless; com algum humor negro, seria o caso de dizer que os usuários tradicionais daqueles espaços degradados só poderiam visitá-los agora na qualidade de turistas ocasionais. Numa palavra, os centros restaurados acabaram se convertendo em cenários para uma vida urbana impossível de ressuscitar.
\end{abstract}

\footnotetext{
${ }^{5}$ Para os autores (p. 128-129), formulou-se um programa de renovação urbana dirigido "para reconstruir a imagem da cidade com arquiteturas emblemáticas de empresas de renome internacional, projetos insígnia, equipamentos culturais e artísticos, festivais, feiras e outros eventos internacionais. Instrumentalizado pela estética e a lógica promocional, o urbanismo se põe a serviço da regeneração socioeconômica criando condições materiais - isto é, espaços qualificados de produção e consumo, adaptados às exigências das novas demandas locais e globais - necessárias para acolher novos usos e funções dinamizadoras. O fim último dessas iniciativas é reforçar a capacidade de Bilbao para competir com outras cidades para atrair novos investidores e consumidores que permitam assegurar vantagens competitivas e relançar uma nova fase de crescimento urbano" [grifo nosso].
} 
Para os países periféricos, o desenvolvimento turístico - a consagração do patrimônio cultural como recurso para o "planejamento estratégico" - é um fenômeno muito mais recente, especialmente depois da década de 1980, quando a integração comercial mais profunda entre países propicia também aos governos nacionais vislumbrar possibilidades de desenvolvimento turístico.

Por isso, a própria idéia de gentrification parece não ser suficiente para dar conta de entender o processo de valorização das áreas centrais e o patrimônio histórico como áreas turísticas em algumas cidades brasileiras. Naturalmente, o processo de volta ao centro é notável - a exemplo das propostas de intervenção na zona central de Salvador (BA), Recife (PE), Rio de Janeiro (RJ) e Porto Alegre (RS); no entanto, isso se dá por atividades que, até o momento, muito se distanciam do desejo de voltar a morar no centro - tal como se observou com o surgimento de uma nova "urban gentry" em Londres, ainda na década de 1960, conforme estudos pioneiros de Ruth Glass para o contexto britânico (UNESCO, 2009).

Mesmo nas chamadas "cidades globais", na acepção de Sassen (1991), ou nas metrópoles dos países do capitalismo central, as atividades de lazer, entretenimento, comércio e cultura também se fazem cada vez mais presentes. No entanto, se conjugam com a re-ocupação ou substituição de moradores de imóveis na zona central - como aponta Barreto Silva (2006, p. 9), "na qual o componente residencial não pode ser dissociado das transformações das paisagens do emprego, do lazer e do consumo". Hammet (2007, p. 333) interpreta os processos de gentrificação vis-a-vis transformações advindas da passagem de sociedades industriais para pós-industriais, especialmente no que diz respeito a preferências culturais e hábitos de consumo.

Nos casos brasileiros - a exemplo de Recife, onde Leite (2004) sugere um processo de gentrificação do Recife Antigo - nota-se uma priorização das atividades comerciais, especialmente vinculadas a lazer, turismo e entretenimento. No Brasil, tanto não se nota um interesse consistente das classes médias por voltar a habitar o centro, como também os projetos de "revitalização" são bastante criticados também por não trazerem soluções efetivas aos problemas habitacionais e, ainda mais, sociais (mendicância, desemprego etc.). 
É justamente por isso que as questões de produção e consumo turístico - enquanto uma expressão do capitalismo contemporâneo - merecem mais estudo no tocante à compreensão das formas urbanas e sociedade atuais ${ }^{6}$. Como parcela do atual estágio da urbanização, o turismo tem, em diferentes graus, participação nas políticas públicas de gestão urbana e na aglutinação de interesses no ambiente urbano.

Como será discutido adiante, o papel do turismo varia quando se analisa a realidade brasileira frente ao contexto europeu ou norte-americano, mas também se podem ver nuanças dentro da própria estrutura sócio-econômica brasileira. Por isso, como forma de dar atenção a estas especificidades nacionais, decidiu-se apresentar o caso de Rio Branco, justamente pelo fato de convencionalmente priorizarem-se estudos das questões de gestão urbana, patrimônio cultural e até pós-modernidade apenas nas grandes metrópoles.

\section{BREVE HISTÓRICO DAS POLÍTICAS PÚBLICAS DO TURISMO NO BRASIL}

Num primeiro momento do desenvolvimento do turismo no Brasil, observado a partir do primeiro Governo Vargas (1930-45), alguns aspectos tecnológicos - indústria, transporte e comunicação - e sociais - trabalho assalariado, ampliação da sociedade urbana, novos hábitos de consumo - estimularam a formação de destinos turísticos no sudeste, com a difusão dos "balneários termais" 7 , os quais, associados a cassinos, entraram em decadência após a proibição do jogo no país, em 1946. Uma "segunda onda" é observada a partir dos anos 1960, quando o tema passou a ser tratado por políticas específicas, ao que se somaram políticas de "integração do território nacional" nos governos militares. Nesse período, o turismo firmou-se como atividade produtiva e começou um processo acentuado de expansão territorial (CRUZ, 2000).

\footnotetext{
${ }^{6}$ Baumann (1999, p. 88) chama o momento atual de "sociedade moderna", mas lembra as considerações de Baladier ("estágio supramoderno") e não negligencia também o "pós-moderno". A propósito, não é objetivo deste artigo discutir, de maneira aprofundada, a questão da pós-modernidade do ponto de vista conceitual, semântico ou estrutural, mas apenas traçar algumas de suas características.

${ }^{7}$ Marras (2007) descreve de maneira pormenorizada a formação de Poços de Caldas (MG) com referência direta a esta primeira fase do turismo brasileiro, atualmente bem pouco significativa se comparada à exuberância da atividade turística em outras partes do país, especialmente litorâneas.
} 
Nas proposições do II PND - Plano Nacional de Desenvolvimento, de 1973, discutidas por Souza (2004), infere-se uma atenção pontual ao turismo. Neste contexto, a Política Nacional de Desenvolvimento Urbano (PNDU) - não aplicada segundo propostas iniciais - previa quatro "grandes áreas" para intervenção de políticas públicas: contenção, controle, dinamização e promoção. Especificamente no tema da "promoção", as áreas turísticas foram foco de atenção especial - no caso, enfatizando as cidades barrocas de Minas Gerais, Rodovia Rio-Santos, cidades antigas do Nordeste brasileiro.

Independentemente de políticas muito definidas, o desenvolvimento do turismo se deu, inicialmente - e é bem verdade que ainda assim se mantém - a partir da exploração de recursos naturais, especialmente por conta do imaginário idílico de paisagens litorâneas ou de florestas idílicas - ícones imagéticos bastante valorizados por públicos do Hemisfério Norte. Vale lembrar que a criação da EMBRATUR - Empresa Brasileira de Turismo (atual Instituto Brasileiro de Turismo, em 1967 estava, de alguma forma, ligada à tentativa de fazer do Rio de Janeiro um destino turístico internacional, em que pese sua estrutura industrial pouco desenvolvida para fazer frente à perda da condição de capital federal (FRATUCCI, 2005).

Nos últimos 20 anos, políticas públicas específicas confirmam o modelo sun and sea, mas apontam para a importância dos bens culturais como mercadorias de consumo. O Programa de Desenvolvimento do Turismo no Nordeste (PRODETUR/NE) resultou de um convênio firmado, em 1996, entre o Banco Interamericano de Desenvolvimento (BID) e o governo brasileiro, tendo o Banco do Nordeste do Brasil como órgão executor. O montante desta fase atingiu US\$ 800 milhões, tendo como agente financeiro majoritário o BID, que estipulou como um dos itens básicos de aplicação dos recursos a recuperação e revitalização do patrimônio cultural (ALLIS, 2003; 2006).

Nesse sentido, o PRODETUR-NE parece dar corpo a uma fase de revitalizações de centros históricos, agora em função de sua potencialidade turística. Esta tendência será desdobrada para outras regiões, associando-se a variadas realidades políticas, sociais e culturais. O que, ao redor do mundo, é bem observável em grandes cidades - incluindo as brasileiras, ainda que com ênfases bem marcadas - parece também deslumbrar as cidades menores e não tão diretamente ligadas às vicissitudes dos grandes centros. É neste sentido 
que a prática de revitalizar, na essência já questionável, parece tomar conta dos discursos de gestores públicos em todo o país.

Este é um fenômeno bem pouco estudado - é dizer, a difusão de práticas de revitalização pelo Brasil, em todas suas nuances e formatos - o que o torna especialmente importante quando observado sob o viés dos estudos turísticos. É válido registrar que, numa sociedade essencialmente desigual, medidas de incentivo ao turismo, uma vez mais, poderão, ser apontadas por suas características excludentes, quando, em realidade, as causas e práticas excludentes se perenizam nos princípios de organização do território.

\section{OLHAR CONTEMPORÂNEO: INTERVENÇÕES URBANAS E TURISMO NO BRASIL}

O patrimônio edificado ou do conjunto dos atributos urbanos como um todo - que Yázigi (2000, 2002, 2003) chama de "patrimônio ambiental urbano" - estão alçando a condição de importantes insumos turísticos. Essa constatação inaugura uma nova fase de intervenção no espaço urbano, já que, pelo menos até a década de 1990, as áreas desvalorizadas pela dinâmica urbana - especialmente o mercado imobiliário - são simplesmente interpretadas como passivo urbano e um ônus do processo de urbanização.

Há experiências de operações urbanas - principalmente em São Paulo (SP) - em que se criam novos valores imobiliários a partir de um conjunto de ações focadas na implantação de infra-estrutura e flexibilização do aparato legal - tal como se observa no eixo sudoeste da capital paulista, nas proximidades do Rio Pinheiros ${ }^{8}$. O que ainda está para ser discutido são os paralelos e especificidades deste fenômeno nas capitais brasileiras visa-vis a realidade européia e norte-americana. A organização sócio-territorial brasileira não atingiu limites tal como se observa em aglomerados urbanos europeus; daí a idéia de que renovação no Brasil e na América Latina guiou-se por demandas e princípios diferentes.

\footnotetext{
${ }^{8}$ Eduardo A. C. Nobre realizou um estudo detalhado sobre o assunto em sua tese de doutorado, em que apresenta o processo de expansão e valorização imobiliária nesta região. NOBRE, E. A. C. Reestruturação econômica e território: expansão recente do terciário na marginal do Rio Pinheiros. Tese (Doutorado). Faculdade de Arquitetura e Urbanismo, Universidade de São Paulo, São Paulo, 2000.
} 
O consórcio entre projetos urbanos e o patrimônio edificado é algo que está regido por outra dinâmica; em linhas gerais, seu vínculo com a valorização imobiliária é errante e, no mais das vezes, ganha contornos políticos em que as imagens urbanas são valorizadas por seu poder simbólico de renovação ou revitalização. Este parece ser um traço notável nas experiências brasileiras, que, por sua natureza, tem vínculo com o desenvolvimento do turismo.

O caso mais representativo deste tipo de intervenção no Brasil está em Salvador (BA) - por sua precocidade na realidade brasileira, que já na década de 1980, recebeu investimentos estaduais no intuito de se construir um destino turístico de porte internacional, que fosse além do turismo sol e praia. Nos últimos vinte anos, esta estratégia - ou seja, intervenções urbanas centradas no patrimônio no fito de atrair turistas - tem se disseminado por todo o Brasil, especialmente fortalecidas por linhas de financiamento do Banco Interamericano de Desenvolvimento (BID), através do Programa de Desenvolvimento do Turismo no Nordeste (PRODETUR) e o Programa Monumenta, que engloba 26 cidades em parceria com os governos Estaduais (PROGRAMA MONUMENTA, 2009).

Nobre (2002) estuda o caso de Salvador (BA) e aponta sérias implicações sociais no processo de regeneração ${ }^{9}$ do centro da cidade, especialmente no Pelourinho. Caracterizada por concentrações de remanescentes coloniais, a área era densamente habitada por populações de baixa renda, o que comumente é interpretado como incongruente aos padrões de turismo internacional.

Já no caso do Plano de Revitalização do Recife Antigo (Pernambuco/PE), realizado a partir de 1993, as restaurações do patrimônio edificado da região central da cidade se baseiam em "uma articulada idéia de intervenção urbana na forma de um longo empreendimento" (LEITE, 2004). De toda maneira, o plano - primeiramente centrado no Pólo da Rua Bom Jesus - deveria redundar na criação de espaços de lazer e diversão,

\footnotetext{
9 O autor cita "regeneração urbana" como um entendimento mais recente na seara das práticas preservacionistas, como sendo responsável por definir intervenções que venham a melhorar o ambiente, a imagem e a segurança da cidade. Por outro lado, renovação urbana (urban renewal) e reabilitação (rehabilitation) seriam processos anteriores, que, com ou sem intervenções físicas, alteraram as densidades urbanas e incrementaram ambientes antes decadentes, respectivamente.
} 
transformando-se, assim, num "espetáculo urbano" capaz de atrair turistas nas escalas nacional e internacional. O caso do Recife é detalhadamente estudado por Leite (2004), que chama atenção para as circunstâncias em que ocorreu o tombamento do Recife Antigo,

\begin{abstract}
O fato é que o processo de "revitalização" se impôs, como um bem sucedido empreendimento, e foi uma das principais defesas para o tombamento do Bairro do Recife. Mais do que isso: o tombamento foi um ato explicitamente político para atender a uma exigência do BID para incluir a cidade do Recife no consórcio que criou o programa Monumenta/BID [...] Essa dimensão mercadológica implica que a racionalidade da preservação tem seu foco direcionado para as práticas que podem agregar valor aos bens culturais, no sentido de possibilitar uma rentabilidade dos investimentos aplicados, acrescidos dos lucros potenciais que o bem restaurado pode propiciar.
\end{abstract}

Recentemente, Vargas e Castilho (2006) apresentaram um conjunto de intervenções em centros urbanos menos discutido ou mais recente - casos de Aracaju (SE), Fortaleza (CE), Belém (PA) e São Luís (MA) - além de rever os projetos instalados nas cidades do Rio de Janeiro e São Paulo. No caso da capital paulista, José (2007) tratou das políticas culturais aplicadas aos processos de revitalização urbana no Centro da cidade, através de uma análise das propostas de intervenção operadas desde a década de 1970.

A cidade de São Luís, com significativo acervo urbano do período de ocupação francesa, exemplifica como os contextos políticos podem interferir para a morosidade das intervenções. O chamado Projeto Reviver, apesar de trazer importantes melhoras no que se refere à conservação física dos edifícios, ainda não resultou em reocupação da área por residências - ainda que o afluxo de turistas venha se expandindo nos últimos anos (PEREIRA, 1997).

Até mesmo João Pessoa e Aracaju, cidades nordestinas com menor expressão turística, investem em propostas de requalificação urbana, no intuito de estruturar uma oferta urbana e turística capazes de atrair fluxos de turistas estrangeiros já consolidados em Salvador e Fortaleza. Notam-se também tentativas de requalificação urbana no Norte do Brasil, como em Belém (Pará), e no Sul, em Porto Alegre (Rio Grande do Sul). No primeiro caso, uma extensa área portuária, às margens do Rio Guamá e da Baía de Guajará, foi reconvertida para fins comerciais, resultando na Estação das Docas - espécie de shopping center gastronômico que privilegia a paisagem a beira-rio. No caso de Porto 
Alegre, as ações tiveram início com a reforma do Mercado Central, também próximo à zona portuária, expandindo-se para o centro da cidade, com a requalificação visual de vias públicas e edifícios de interesse histórico e estético (VARGAS e CASTILHO, 2006).

No que se refere às preocupações com o patrimônio em si, Leite (2004), ao lembrar Arantes (2001, p. 71) ao tratar do tema do "culturalismo de mercado", considera que

[...] a tônica central do "planejamento estratégico", eufemismo acanhado para gentrification e espécie de onda neoconservadora do urbanismo, é justamente a transformação da cultura em um segmento de mercado e da própria economia em um assunto cultural.

Neste contexto, o turismo cultural - numa versão brasileira ${ }^{10}$ - floresce em contextos urbanos onde subsistem fragmentações sociais e espaciais, mas que sugerem novas possibilidades no momento da re-estruturação das economias urbanas. Num discurso pasteurizado, gestores locais justificam o empenho financeiro nos projetos de “requalificação" também considerando os dividendos da visitação turística.

Neste movimento, o tecido urbano, especialmente em suas porções mais antigas e quase sempre centrais, é incorporado a políticas de "empresariamento urbano" (HARVEY, 1996; 2005). Nas políticas urbanas, a despeito do essencial significado dos bens culturais ${ }^{11}$, pesam as análises de mercado, que apontam para tendências de expansão no setor turístico. Assim, o turismo cultural impõe-se como um somatório de medidas preservacionistas e de interesses econômicos, matizados entre si de forma heterogênea segundo os fatores locais como organização da sociedade civil e propostas de investimento de grupos de interesse.

\footnotetext{
${ }^{10}$ Para o Ministério do Turismo do Brasil, "turismo cultural compreende as atividades turísticas relacionadas à vivência do conjunto de elementos significativos do patrimônio histórico e cultural e dos eventos culturais, valorizando e promovendo os bens materiais e imateriais da cultura" (BRASIL, Ministério do Turismo. Turismo cultural: orientações básicas. Brasília: 2008). Para os propósitos desta discussão, nota-se, portanto, que esta definição é bastante genérica, que não abarca, na totalidade, as questões envolventes à realidade do desenvolvimento real do turismo nos contextos urbanos apontados.

${ }^{11}$ Arantes (2002, p. 146) considera que, da forma como a "era da cultura" se consolida nas gestões urbanas, a função precípua da cultura - qual seja, esclarecimento - está a ser substituída por um "consumo de cultura", algo que a autora entende como "fetichismo" ou "uma inércia aparentemente incontrolável".
} 


\section{RIO BRANCO (AC): UMA PÓS-MODERNIDADE TRUNCADA}

O Estado do Acre historicamente esteve pouco relacionado com os grandes ciclos econômicos brasileiros. Tendo sido o último ponto de expansão de fronteira brasileira ao noroeste da Amazônia, no fim da primeira metade do século XIX, foi apenas no início do século XX, quando o Estado definitivamente se confirma como uma unidade da federação, que assistiu ao surto de exploração e beneficiamento primário da borracha - fenômeno não muito vigoroso se comparado com os demais ciclos econômicos brasileiros. Já no caminho descendente da cadeia produtiva da borracha, o Estado ficou amplamente conhecido pelas contestações e demandas dos seringueiros, cuja organização estava centralizada na figura de Chico Mendes, assassinado em 1989 (COSTA, 2007).

Em 2008, passados 20 dos episódios que levaram à sua exposição mundial pela exploração altamente desigual dos recursos da floresta, o Acre, com cerca de 700 mil habitantes, continua com mais de $98 \%$ da cobertura vegetal original (IBGE, 2008). Isso parece ser o motivo que dá segurança para que a administração atual se intitule como o "governo da floresta". Esta fase da gestão pública acreana - ou seja, desde meados dos anos 1990 - é apontada como "modernizadora" daquela porção do Norte brasileiro, tendo em vista que se vêm propondo ações "progressistas" e entendidas como socializantes em termos de educação, saúde, gestão ambiental, desenvolvimento econômico.

Independentemente de se pôr à observação e crítica estas ações, chama a atenção o processo de "renovação" pelo qual passou a capital do Estado, Rio Branco, convertendo-se de tacanho entreposto comercial a uma capital salpicada de obras públicas de feições pósmodernas. Seguindo referências observadas em outras partes do país, a área core da cidade, onde se iniciou sua ocupação e se mantêm alguns ícones arquitetônicos que lastreiam a história oficial da cidade, passou por um processo de requalificação.

O Mercado Velho passou por restauro, convertendo-se em espaço de lazer especialmente na esplanada de bares que se instalaram na área externa. A paisagem ribeirinha, onde está o mercado, foi acrescida de uma luminosa ponte para pedestres (Figura 1), cujas luzes se conjugam com o neón aplicado às fachadas dos edifícios de 
arquitetura vernácula (Figura 2), que um dia formaram um conjunto urbano estruturante da vida social local.

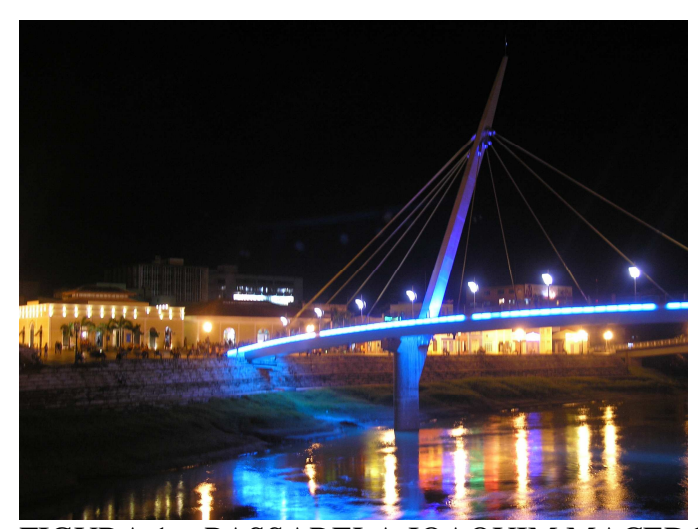

FIGURA 1 - PASSARELA JOAQUIM MACEDO (RIO ACRE)

FOTO: AUTOR (JAN. 2008)

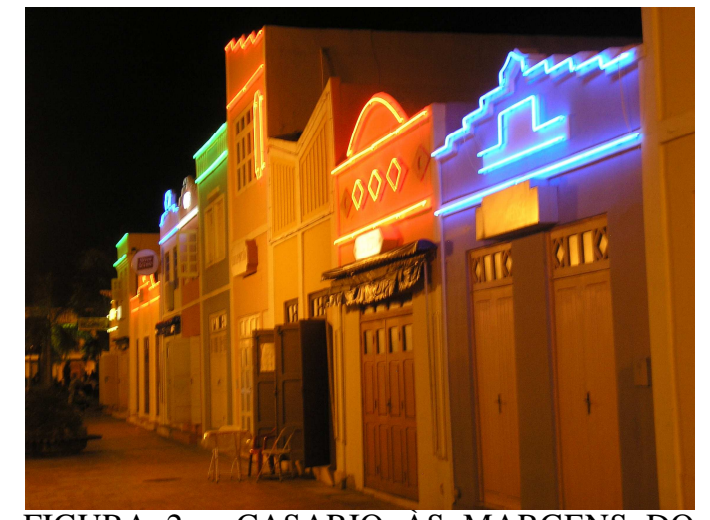

FIGURA 2 - CASARIO ÀS MARGENS DO RIO ACRE

FOTO: AUTOR (JAN. 2008)

Alguns aspectos estéticos são questionáveis, ainda que, do ponto de vista do efeito, estas ações parecem surtir resultado: criou-se um conjunto de símbolos e imagens capazes de instalar a cidade no catálogo de destinos turísticos nacionais. No entanto, em termos de competitividade, a cidade e o Estado estão em posições desfavoráveis no contexto turístico nacional, principalmente por sua localização (distante de centros emissores tradicionais) e por apresentar acervo turístico ainda pouco competitivo frente a alguns nichos tradicionais e populares no país (como o sun and sea no litoral nordestino).

A cidade já conta com um novo aeroporto a 30 quilômetros do centro e muitos são os folhetos e brochuras promocionais da região - sendo que uma parte delas faz menção ao roteiro integrado entre Brasil (Acre), Peru e Bolívia, fartamente distribuídos nas feiras de turismo nacionais. Neste sentido, receber ou não turistas, para o momento, parece uma preocupação secundária: trata-se, por ora, de aparatar a cidade de atributos e dispensar-lhe todos os tratamentos cabíveis para articulá-la ao circuito de valorização das imagens urbanas renovadas. Com isso, almeja-se sinalizar, ao país e ao mundo, que o Acre, de fato, não é mais um espaço isolado - tanto geográfica, quando simbolicamente - na imensidão da floresta (ainda que o tema "floresta" seja estrategicamente lembrado em todos os assuntos da vida local). Para tanto, na acepção de Arantes (2002), o urbano e, por 
consequiência, as cidades comportam um "repertório de símbolos", os quais, por quaisquer motivos que sejam, vão além da significação direta para a vida urbana cotidiana.

Este ordenamento ideológico, levado a termo por um projeto urbano em uma cidade fora da constelação das principais capitais brasileiras, faz refletir sobre a contraposição talvez justaposição - moderno/pós-moderno. O fenômeno parece especialmente instigante justamente porque localizado num ponto desprivilegiado na hierarquia urbana brasileira e, portanto, despojada das feições urbanas convencionais na análise das intervenções urbanas contemporâneas (voltadas ou não ao turismo). Mas, ao que parece, ações e ideologias entendidas como pós-modernas se fazem sentir também em Rio Branco.

Daí porque considerar-se esta situação como uma pós-modernidade truncada, já que, por mais que a cidade também passe por vicissitudes próprias do desenvolvimento econômico e social, são elas muito distintas das grandes metrópoles do capitalismo central. Ou seja, à re-apropriação de espaços urbanos por novas atividades - incluídos os ganhos e as perdas no jogo de forças da gestão das cidades - pressupõe-se, em geral, um passado industrial e, por conseguinte, um claro aumento do setor terciário em detrimento do secundário. No caso de Rio Branco, a cidade e especialmente a zona urbana estudada não fazem parte desta realidade - ainda que a noção de transformação de usos e re-uso de estruturas esteja aí presente.

Quando se recorda a discussão sobre "tradição" e "relíquia", encetada por Leite (2004), percebe-se que a tentativa de criar visibilidade e um sentimento de pertencimento a esta intervenção em Rio Branco se baseia na elevação do mito fundador da cidade e do Estado à condição de tradição coletiva. Isso, no entanto, se dá de forma seletiva, elegendose alguns pontos da trama urbana às margens do Rio Acre como forma de concentrar o sentimento de unidade cultural. Na verdade, também lembrando Arantes (2001), não se tratam de providências meramente altruístas, senão assimilação, por parte do governo local, de ferramentas de gestão urbana amparadas na valorização do patrimônio. Vale lembrar o que Leite (2004) considera, ao estudar o caso do Recife Antigo:

Os projetos contemporâneos de "revitalização" recolocaram os velhos centros históricos na pauta das políticas públicas e transformaram-se em um agudo esforço das gestões municipais na recuperação das políticas econômicas locais, 
através da revalorização de suas tradicionais localidades. Transformado em mercadoria cultural, o patrimônio histórico parece adequar-se à nova lógica do mercado, abrindo-se a parcerias com a iniciativa privada, que tem investido nessas áreas como um bom e lucrativo negócio [grifo nosso].

De maneira bem simples, equivale a comparar a assimilação das práticas de planejamento estratégico consagrada, na América do Sul, por Buenos Aires e, em menor escala, Rio de Janeiro, em que, segundo Bidou-Zachariasen (2006), o modelo catalão, cujo estandarte é Barcelona, chega a representar um paradigma a ser seguido.

Assim, talvez seguindo um paradigma brasileiro, que se desenha nas cidades da costa ou do Centro-Sul, Rio Branco - e talvez, em certa medida, Belém do Pará, por sua condição de isolamento na rede urbana nacional - busque aparatar-se de uma cena urbana que lhe resulte uma imagem pós-moderna.

Conforme se argumenta neste trabalho, a realidade pós-moderna acreana parece estar truncada, já que as propostas de intervenção urbana centrada no patrimônio não seguem pelo menos não ainda - o mesmo percurso de valorização de outras cidades do Brasil: o afluxo de visitantes é irrisório e, como sendo uma cidade pouca exposta aos formadores de opinião, essas parcerias com a iniciativa privada não se concretizaram.

\section{6 À GUISA DE CONCLUSÃO}

Tendo em vista as intervenções urbanas nas principais cidades brasileiras, emergem inquestionáveis discrepâncias e distorções de caráter social e cultural. No entanto, como cidades centrais na trama urbana brasileira, sua integração com a atividade turística parece mais factível com a real possibilidade de receberem fluxos de visitantes. Desde meados dos anos 1990, as capitais litorâneas do Nordeste brasileiro estão cada vez mais conectadas diretamente com cidades européias, principais emissores internacionais para a região.

Assim, a despeito das críticas, o que soa curioso é que, em algumas situações é que uma tendência que parece estar carregada de pós-modernidade - as intervenções espetaculares, para fazer menção à idéia de Debord (1997) - se difundem para outras partes do país, onde nem a atração de visitantes parece razoável. E, considerando que "turistificar" 
- nos termos de Knafou (2001) o território é, também, uma das preocupações dessas intervenções, o turismo acaba sendo um subterfúgio questionável - não apenas do ponto de vista dos impactos desta atividade, senão também da efetiva capacidade de existir!

Não é sem sentido lembrar os comentários de Arantes (2001) sobre as intervenções urbanas, ao dizer que, após as transformações, determinadas porções do território urbano acabam sendo acessíveis ao visitante incidental - como se todos passassem a ser turistas. E mais: visitantes que sejam "solváveis" (VAINER, 2002), ou seja, capazes de consumir determinadas "mercadorias culturais" (LEITE, 2004).

Neste sentido, o panorama exposto parece um tanto mais irônico numa realidade tão discrepante do imaginário urbano tradicional (ou seja, representado por densas aglomerações metropolitanas). Fracamente integrado à economia e à rede urbana brasileira, o Estado do Acre sequer viveu um típico surto industrial, se comparado com as regiões litorâneas do país, por exemplo. Destarte, segundo o conceito de Hammet (2007), os processos de gentrificação poderiam ser compreendidos no seio de sociedades pósindustriais - o que, obviamente, pressupõe um contexto urbano industrial precedente.

Com este artigo, não se propõe uma crítica irrefutável ou uma sacralização ideológica aos projetos urbanos. O que se busca com estudos como este, é questionar a assimilação acrítica de alguns preceitos de gestão urbana, como sendo tais intervenções uma panacéia para os problemas urbanos - geralmente, algo bastante comum no discurso relacionado aos projetos de desenvolvimento turístico. Com isso, almeja-se uma melhor compreensão do fenômeno do turismo na contemporaneidade - invariavelmente vinculado à questão urbana - e, ainda, encaminhamentos mais sensatos para a operacionalização da atividade, sejam na academia, nas políticas públicas e nos negócios.

Em suma, o que se pode observar é que as providências no tocante ao cuidado com o patrimônio e as propostas de administração do espaço urbano representam valores e parâmetros observáveis com freqüência cada vez mais intensa em outras situações do próprio país e, de certa forma, do mundo. Neste contexto, o turismo, o lazer e o entretenimento são temas paulatinamente recorrentes nas políticas de gestão do território independentemente da significância (econômica, política ou cultural) das cidades na trama urbana nacional ou até internacional. Ao se observar a realidade de Rio Branco, pôde-se 
argumentar que, ainda que a região historicamente seja reconhecida por suas paisagens naturais amazônicas, o acervo urbano, acrescido de intervenções voltadas à valorização do patrimônio, assume papel de destaque no desenvolvimento turístico.

Ao fim e ao cabo, o caso estudado mostra que as ações de desenvolvimento turístico, articuladas às práticas de gestão urbana, não se restringem aos grandes aglomerados urbanos - como nos casos emblemáticos de Buenos Aires ou das principais capitais turísticas do Brasil, para ficar na realidade latino-americana. Outrossim, o turismo, o lazer e o entretenimento são temáticas em consolidação no rol de providências dos gestores locais, por menos óbvia que possa ser a relação daquela cidade ou região com os interesses e a origens dos mercados turísticos emissores.

Ainda que o sucesso dos destinos turísticos dependa de ações mais complexas do que tais projetos urbanos, a construção da imagem de uma cidade renovada, executada através de reparos urbanos pontuais, está diretamente lastreada na perspectiva de atração de visitantes. Inclusive no Acre.

\section{REFERÊNCIAS}

ALLIS, T. Geografia regional e arqueologia como subsídios para o estudo do turismo: o caso do Parque Nacional da Serra da Capivara (PI). Monografia (Graduação). Escola de Comunicações e Artes, Universidade de São Paulo, São Paulo, 2003.

Turismo, patrimônio cultural e transporte ferroviário: um estudo sobre ferrovias turísticas no Brasil e na Argentina. Dissertação (Mestrado). Programa de PósGraduação em Integração da América Latina, Universidade de São Paulo, São Paulo, 2006.

ARANTES, O. B. F. Urbanismo em fim de linha e outros estudos sobre o colapso da modernização arquitetônica. São Paulo: EDUSP, 2001.

Uma estratégia fatal: cultura nas novas gestões urbanas. In: ARANTES, O.; VAINER, C.; MARICATO, E. (Orgs.). Cidade do pensamento único: desmanchando conceitos. Petrópolis: Vozes, 2002.

ARGAN, G. C. História da arte como história da cidade. São Paulo: Martins Fontes, 1998. 
BAUMANN, Z. Globalização: as conseqüências humanas. Rio de Janeiro: Jorge Zahar Editora, 1999.

BARRETO SILVA, H. M. Apresentação. In: BIDOU-ZACHARIASEN, C. (Org.) De volta à cidade: dos processos de gentrificação às políticas de "revitalização" dos centros urbanos. São Paulo: Annablume, 2006.

BIDOU-ZACHARIASEN, C. Introdução. In: (Org.) De volta à cidade: dos processos de gentrificação às políticas de "revitalização" dos centros urbanos. São Paulo: Annablume, 2006.

BRASIL, Ministério do Turismo. Turismo cultural: orientações básicas. Brasília: 2008

CANCLINI, N. G. A globalização imaginada. São Paulo: Iluminuras, 2003.

COSTA, A. L. R. M. F. Acre, história e arquitetura: tradição vernácula e moderna num ambiente de floresta. Disponível em: <www.vitruvius.com.br/arquitextos/arq000/esp412.asp>. Acesso em: 25/07/2008.

CRUZ, R. C. A. Política de turismo e território. São Paulo: Contexto, 2000.

DEBORD, G. Sociedade do espetáculo: comentário sobre a sociedade do espetáculo. Rio de Janeiro: Contraponto, 1997.

FRATUCCI, A. C. A formação e o ordenamento territorial do turismo no Estado do Rio de Janeiro a partir da década de 1970. In: BARTHOLO, R.; DEMALARO, M; BADÍN, L. (orgs.). Turismo e sustentabilidade no Estado do Rio de Janeiro. Rio de Janeiro: Garamond, FAPERJ, 2005.

HAMMET, C. Gentrification, posindustrialism, and industrial and occupational restructuring in global cities. In: BRIDGE, G.; WATSON, S. A companion to the city (org). Oxford, Blackwell Publishing, 2007.

HARVEY, D. Do gerenciamento ao empresariamento urbano: a transformação da administração urbana no capitalismo tardio. In: Revista Espaço \& Debates, São Paulo, 1996, v. 16, n. 39, p. 48-64.

. Condição pós-moderna. 14 ed. São Paulo: Loyola, 2005.

IBGE. Potencial florestal do Estado do Acre - Relatório técnico: resultados preliminares. Disponível em: <www.ibge.gov.br>. Acesso em: 06/04/2008.

JOSÉ, B. K. Políticas culturais e negócios urbanos: a instrumentalização da cultura na revitalização do centro de São Paulo - 1975-2000. São Paulo: Annablume, FAPESP, 2007. 
KNAFOU, R. Turismo e território: para um enfoque científico do turismo. In: RODRIGUES, A. B. (Org.). Turismo e geografia: reflexões teóricas e enfoques regionais. São Paulo: Hucitec, 2001.

LEITE, R. P. Contra-usos da cidade: lugares e espaço público na experiência urbana contemporânea. Campinas: Ed. Unicamp; Aracaju: Ed. UFS, 2004.

MARRAS, S. A propósito de águas virtuosas: formação e ocorrências de uma estação balneária no Brasil. Belo Horizonte: Ed. UFMG, 2007.

NOBRE, E. A. C. Reetruturação econômica e território: expansão recente do terciário na marginal do Rio Pinheiros. Tese (Doutorado). Faculdade de Arquitetura e Urbanismo, Universidade de São Paulo, São Paulo, 2000.

NOBRE, E C. Urban regeneration experiences in Brazil: historical preservation, tourism development and gentrification in Salvador da Bahia. In: Urban Design International, 2002, v. 7, n. 2, p. 109-124.

PEREIRA, L. L. Praia Grande: uma história de resistência. Monografia (Graduação). Centro de Ciências Exatas e Naturais, Universidade Estadual do Maranhão, São Luís, 1997. Disponível em: <http://www.geocities.com/Paris/Louvre/4343/saoluis.html>. Acesso em: 29/03/2009.

PROGRAMA Monumenta. Disponível em: <www.monumenta.gov.br>. Acesso em: 20/03/ 2009.

REIS FILHO, N. G. São Paulo e outras cidades: produção e degradação dos espaços urbanos. São Paulo: Hucitec, 1994

RODRIGUEZ, A.; ABRAMO, P. Reinventar a cidade: urbanismo, cultura e governança na regeneração de Bilbao. In: COELHO, T. (Org.). A cultura pela cidade. São Paulo: Iluminuras; Itaú Cultural, 2008.

SASSEN, S. The global city. Princeton: Princeton University Press, 1991.

SILVA, R. C. M. A urbanidade na cidade contemporânea entre fronteiras e trincheiras. In: . (Org). A cidade pelo avesso: desafios do urbanismo contemporâneo. Rio de Janeiro: Viana \& Mosley, PROURB, 2006.

SOJA, E. Postmetropolis: critical studies of cities and regions. Oxford: Blackwell, 2000.

SOUZA, M. A. A. O II PND e a política urbana brasileira: uma contradição evidente. In: DEÁK, C.; SCHIFFER, S. T. R. (Orgs.). O processo de urbanização no Brasil. São Paulo: EDUSP, 2004. 
UNESCO. From gentrification to forced eviction - how should economic competitiveness be reconciled with social sustainability in historical districts? Disponível em: <www.unesco.org.br>. Acesso em: 05/10/09.

VAINER, C. B. Pátria, empresa e mercadoria: notas sobre a estratégia discursiva do Planejamento Estratégico Urbano. In: ARANTES, O.; VAINER, C., MARICATO, E. Cidade do pensamento único: desmanchando conceitos. Petrópolis: Vozes, 2002.

VARGAS, H. C., CASTILHO, A. L. H. (Orgs.) Intervenções em centros urbanos: objetivos, estratégias e resultados. Barueri: Manole, 2006.

VASCONCELLOS, L. M.; MELLO, M. C. F. Re: atrás de, depois de... In: VARGAS, H. C.; CASTILHO, A. L. H. (Orgs.). Intervenções em centros urbanos: objetivos, estratégias e resultados. Barueri: Manole, 2006

YÁZIGI, E. O mundo das calçadas. São Paulo: Humanitas/FFLCHOUSP, Imprensa Oficial, 2000.

(Org.) Turismo e paisagem. São Paulo: Contexto, 2002.

Civilização urbana, planejamento e turismo: discípulos do amanhecer. São Paulo: Contexto, 2003.

Recebido em: 15/04/2009

Aprovado em: 15/05/2009 